\title{
Optimization for Fenton Process in Removal of COD for Landfill Leachate Treatment
}

\author{
María Santin-Gusman, Javier Moreno-Andrés, Mónica Cisneros-Abad, and Silvio Aguilar-Ramírez
}

\begin{abstract}
Present study has the aimed to assess the percentage of removal of chemical oxygen demand (COD) of non-biodegradable leachate from the landfill in the city of Loja (Ecuador) to be subjected to a Fenton process. Different concentrations of $\mathrm{H}_{2} \mathrm{O}_{2}$ and $\mathrm{FeSO}_{4}$ were combined in acidic $\mathrm{pH}$ values, obtaining removals close to $80 \%$ with a concentration of $500 \mathrm{ppm}$ of $\mathrm{H}_{2} \mathrm{O}_{2}$ and $1000 \mathrm{ppm}$ of $\mathrm{FeSO}_{4}$ at $\mathrm{pH} 4$, thus establishing an optimum working radius $\mathrm{H}_{2} \mathrm{O}_{2} / \mathrm{FeSO}_{4}$ equal to 0.5. Through Box-Behnken statistical analyses were determinates the significant factors, which correspond to the concentration of $\mathrm{H}_{2} \mathrm{O}_{2}$ and $\mathrm{FeSO}_{4}$ employed. With this information the process was optimized, reaching a theoretical removal of $81 \%$ at concentrations of $312 \mathrm{ppm}$ of $\mathrm{H}_{2} \mathrm{O}_{2}$ and 1087 ppm of $\mathrm{FeSO}_{4}$ at $\mathrm{pH} 4$. It was observed in this process removal of $79 \%$ of turbidity, $33 \%$ of Nitrates and $89 \%$ of Phosphates.
\end{abstract}

Index Terms-Fenton, landfill leachate, COD removal.

\section{INTRODUCTION}

Population growth attached to urban and industrial development, carry associated an increase in waste generation, and consequently, the removal of it, which usually are deposited in landfills [1].

Leachates are liquids commonly generated and associated with landfill [2]. The own humidity of the waste and the rainwater that percolates through them react with the products of decomposition of organic matter that is deposited in these locations, generating a highly polluting product [3]-[5].

A leachate is generally characterized by a strong odor and a dark color as well as retaining a large number of contaminants [6] which are divided into 4 groups : dissolved organic matter represented by parameters such as Chemical Oxygen Demand (COD), macro inorganic components, heavy metals and xenobiotic organic compounds from industrial and household chemicals present in low concentrations (typically less than $1 \mathrm{mg} / \mathrm{l}$ of individual compounds) [7].

The leachate composition is variable and depends on many factors such as age, environmental conditions, type of waste and operating systems within the landfill [2], [8], [9].

Young or middle-aged leachate (less than 10 years old), are acidogenic type, they have a high organic load of low molecular weight and biodegradability (Biological Oxygen

Manuscript received October 29, 2014; revised March 18, 2015.

María Santin-Gusman, Mónica Cisneros-Abad, and Silvio Aguilar-Ramírez are with the Environmental Engineering Department. Technical University of Loja, Ecuador (e-mail: mlsantin@utpl.edu.ec, mjcisneros@utpl.edu.ec, sdaguilar@utpl.edu.ec).

Javier Moreno-Andrés is with the Environmental Technologies Department, Faculty of Sea and Environmental Sciences, University of Cádiz, Spain (e-mail: javier.moreno@uca.es).
Demand - $\mathrm{BOD}_{5} / \mathrm{COD}$ ) between 0.6 and 1 [10]. While old leachate (over 10 years old) is methanogenic type, have a high concentration of organic matter where the refractory type is predominantly and therefore are not biodegradable with an index $\mathrm{BOD}_{5} / \mathrm{COD}<0.3$ because this inhibits biomass action [3], [11], [12].

Among the different types of physicochemical systems, advanced oxidation processes (AOPs) have been reported as one of the most efficient methods to degrade a wide variety of organic compounds of refractory type that are presented in the leachate due to the generation of hydroxyl radicals $(\cdot \mathrm{OH})$ [8], [13].

Within these processes Fenton 's reagent $\left(\mathrm{Fe}^{++}, \mathrm{H}_{2} \mathrm{O}_{2}\right)$ has been widely used because it is efficient, easy to deal, it reacts well with organic compounds and does not produce toxic compounds during oxidation [1].

The Fenton process in water produces. $\mathrm{OH}$ radicals in the absence of organic compounds. According to the following reactions [13]:

$$
\begin{aligned}
& \mathrm{Fe}^{2+}+\mathrm{H}_{2} \mathrm{O}_{2} \rightarrow \mathrm{Fe}^{3+}+\bullet \mathrm{OH}+\mathrm{OH}^{-} \\
& \mathrm{Fe}^{3+}+\mathrm{H}_{2} \mathrm{O}_{2} \rightarrow \mathrm{Fe}^{2+}+\bullet \mathrm{HO}_{2}+\mathrm{H}^{+}
\end{aligned}
$$

Oxidation of ferrous ions to ferric ions begins and catalyzes the decomposition of hydrogen peroxide molecules giving as a result the rapid generation of hydroxyl radicals (Eq. (1)), This reactions depends on the $\mathrm{pH}$ [14]. So that in the absence of any other oxidizable substance, the net reaction of $\mathrm{H}_{2} \mathrm{O}_{2}$, gives as result the formation of $\mathrm{H}_{2} \mathrm{O}$ and $\mathrm{O}_{2}$ catalyzed by iron [10].

TABLE I: CHARACTERIZATION OF LEACHATE

\begin{tabular}{lllll}
\hline \hline Parameters & Units & Value $^{*}$ & $\begin{array}{l}\text { Lower 95\% } \\
\text { confidence } \\
\text { interval }\end{array}$ & $\begin{array}{l}\text { Upper 95 \% } \\
\text { confidence } \\
\text { interval }\end{array}$ \\
\hline $\begin{array}{l}\text { Dissolved } \\
\text { Oxygen }\end{array}$ & $\mathrm{mg} / \mathrm{l}$. & 3.50 & 2.94 & 4.05 \\
pH & $\mathrm{pH}$ units & 8.42 & 8.30 & 8.55 \\
Turbidity & $\mathrm{NTU}$ & 39.38 & 30.91 & 47.84 \\
$\begin{array}{l}\text { Total } \\
\text { Suspended }\end{array}$ & $\mathrm{mg} / \mathrm{l}$. & 224.75 & 159.81 & 289.69 \\
$\begin{array}{l}\text { Solids } \\
\text { Sulfates }\end{array}$ & $\mathrm{mg} / \mathrm{l}$. & 72.09 & 61.76 & 82.41 \\
Total Nitrogen & $\mathrm{mg} / \mathrm{l}$. & 1274.05 & 1126.49 & 1421.61 \\
COD & $\mathrm{mg} / \mathrm{l}$. & 2296.00 & 1917.47 & 2674.53 \\
BOD & $\mathrm{mg} / \mathrm{l}$. & 708.32 & 538.47 & 878.18 \\
Alkalinity & $\mathrm{mg} / \mathrm{l}$. & 6034.38 & 4768.63 & 7300.12 \\
Fecal coliform & $\mathrm{UFC} / 100$ & 45062.50 & 33220.70 & 56904.30 \\
\hline \hline
\end{tabular}

*Average for 16 samples taken from Loja's landfill

There have been several studies on the basis of the 
application of system for the treatment of landfill leachate, which have reported promising results reaching removals between $60 \%-75 \%$ COD [10], [12], [15]-[18].

Taking into account the importance of natural resources and the level in that the leachate affects the environment was proposed to do the present research work with the main goal to optimize the Fenton process for the treatment of these fluids.

\section{MATERIAL AND METHODS}

\section{A. Sampling and Characterization}

The leachate collected for the present study was taken from Loja's Landfill, located in southern of Ecuador. Was made a total of 16 sampling on the basis of standard INEN 2169:98, the samples were transported to the laboratory and kept on refrigeration at $4{ }^{\circ} \mathrm{C}$ for the subsequent analysis. Results obtained from the characterization are shown in Table I. All of these analyses were developed under standardized methodology APHA [19].

\section{B. Experimental Procedure}

To evaluate and optimize the Fenton process was chosen a random experimental design to laboratory scale. Were considered some variables like $\mathrm{pH}$, concentration of hydrogen peroxide $\left(\mathrm{H}_{2} \mathrm{O}_{2}\right)$ and concentration of ferrous sulfate $\left(\mathrm{FeSO}_{4}\right)$. Table $\mathrm{II}(\mathrm{a})$ shows the encrypted experimental combinations where: -1 corresponds to the lowest concentration of reagent, 0 to the average concentration and +1 to the highest concentration evaluated. Table II(b) shows the concentrations used for each of the experiments.

All experiments were carried out into a glass reactor with 21. of capacity using jar-test equipment (Phipps \& Bird) with flat stirring vanes. It was used as batch reactor. A liter of leachate was placed into the glass reactor and then the $\mathrm{pH}$ was conditioned according to the provisions of the experimental design using 95-97\% $\mathrm{H}_{2} \mathrm{SO}_{4}$ (Sigma - Aldrich). The Fenton reaction was carried out by the addition of $30 \% \mathrm{H}_{2} \mathrm{O}_{2}$ (Fisher Scientific) and then $\mathrm{FeSO}_{4} \cdot 7 \mathrm{H}_{2} \mathrm{O}$ (Baker Analyzed); after this, the glass reactor was carried to the jar-test equipment where the sample was subjected to a rapid mixing of $250 \mathrm{rpm}$ for 80 seconds and slowly mixed for 20 minutes at 30rpm.

Once the stirring is finished, the sample was transferred to a graduated cylinder (test-tube) with $1000 \mathrm{ml}$. of capacity for precipitating the sludge formed; during a period of 2 hours. The final sampling was made taking an aliquot of supernatant liquid.

To perform COD analysis was used a thermal reactor HACH DRB 200 and a HACH DR 2800 spectrophotometer.

The expression used to determine the COD removal $(\%)$ achieved was the follows:

$$
\frac{C O D_{\text {initial }}-C O D_{\text {final }}}{C O D_{\text {initial }}} \times 100
$$

Parameters such as: Nitrates and Phosphates were determined in the spectrophotometer. The $\mathrm{pH}$ was measured with a pH-meter HANNA 8520 while the turbidity was measured using a HACH $2100 \mathrm{~N}$ turbidimeter.

All analyzes were carried out according to standard methods [19].

\section{Statistical Analysis}

The experimental design proposed corresponds to a statistical model of response surface type Box Behnken [20], [21].

This model produces a quadratic response surface equal to:

$$
\begin{aligned}
& \% C O D_{\text {removal }}=b_{0}+b_{1} \operatorname{Var} A+b_{2} \operatorname{Var} B+b_{3} \operatorname{Var} C+ \\
& +b_{1,1}(\operatorname{Var} A)^{2}+b_{2,2}(\operatorname{Var} B)^{2}+b_{3,3}(\operatorname{Var} C)^{2}
\end{aligned}
$$

To determinate the significance of the factors at a confidence level of $95 \%$, three replicates to the central value were carried (Table II). Values of the coefficients are contrasted with the value of the expanded uncertainty $U_{\text {exp. }}$.

If: $b_{i} \leq U_{\text {exp }}$, the factor corresponding to the coefficient does not affect significantly the process.

\begin{tabular}{cccc}
\multicolumn{5}{c}{ TABLE II: EXPERIMENTAL DESIGN } \\
\cline { 2 - 4 } & \multicolumn{4}{c}{ II(A): CODED VALUES } \\
\hline $\mathrm{N}^{\mathrm{o}}$ & $\mathrm{H}_{2} \mathrm{O}_{2}$ & $\mathrm{FeSO}_{4}$ & $\mathrm{pH}$ \\
\hline 1 & -1 & -1 & 0 \\
2 & 1 & -1 & 0 \\
3 & -1 & 1 & 0 \\
4 & 1 & 1 & 0 \\
5 & -1 & 0 & -1 \\
6 & 1 & 0 & -1 \\
7 & -1 & 0 & 1 \\
8 & 1 & 0 & 1 \\
9 & 0 & -1 & -1 \\
10 & 0 & 1 & -1 \\
11 & 0 & -1 & 1 \\
12 & 0 & 1 & 1 \\
$13^{*}$ & 0 & 0 & 0 \\
\hline \hline
\end{tabular}

\begin{tabular}{lccc}
\multicolumn{4}{c}{$\mathrm{II}(\mathrm{B}):$ VALUES OF CONCENTRATION } \\
\hline \hline $\mathrm{N}^{\mathrm{o}}$ & $\mathrm{H}_{2} \mathrm{O}_{2}(\mathrm{ppm})$ & $\mathrm{FeSO}_{4}(\mathrm{ppm})$ & $\mathrm{pH}$ \\
\hline 1 & 500 & 500 & 4 \\
2 & 2000 & 500 & 4 \\
3 & 500 & 1000 & 4 \\
4 & 2000 & 1000 & 4 \\
5 & 500 & 750 & 3 \\
6 & 2000 & 750 & 3 \\
7 & 500 & 750 & 5 \\
8 & 2000 & 750 & 5 \\
9 & 1000 & 500 & 3 \\
10 & 1000 & 1000 & 3 \\
11 & 1000 & 500 & 5 \\
12 & 1000 & 1000 & 5 \\
13 & 1000 & 750 & 4 \\
\hline \hline *Number 13 experiment represents the central point
\end{tabular}

\section{Optimum Point Determination}

The first and second derivatives of the polynomial regarding to the significant variables are calculated. With these values the determinant of the Hessian matrix is constructed to determine whether the stationary point is a maximum, minimum or indefinite.

\section{RESULTS AND DISCUSSION}

In the next section are detailed the results obtained in the experimental process in order to evaluate the efficiency of 
Fenton process for treatment of landfill leachate.

TABLE III: RESULTS OF COD REMOVAL

\begin{tabular}{ccccc}
\multicolumn{5}{c}{ TABLE III: RESULTS OF COD REMOVAL } \\
\hline \hline $\mathrm{N}^{\mathrm{o}}$ & $\begin{array}{c}\mathrm{H}_{2} \mathrm{O}_{2} \\
(\mathrm{ppm})\end{array}$ & $\begin{array}{c}\mathrm{FeSO}_{4} \\
(\mathrm{ppm})\end{array}$ & $\mathrm{pH}$ & $\begin{array}{c}\text { COD Removal } \\
(\%)\end{array}$ \\
\hline 1 & 500 & 500 & 4 & 24,3 \\
2 & 2000 & 500 & 4 & 12,5 \\
3 & 500 & 1000 & 4 & 79,5 \\
4 & 2000 & 1000 & 4 & 59,1 \\
5 & 500 & 750 & 3 & 58,3 \\
6 & 2000 & 750 & 3 & 30,2 \\
7 & 500 & 750 & 5 & 75,2 \\
8 & 2000 & 750 & 5 & 37,8 \\
9 & 1000 & 500 & 3 & 60,5 \\
10 & 1000 & 1000 & 3 & 61,8 \\
11 & 1000 & 500 & 5 & 37,0 \\
12 & 1000 & 1000 & 5 & 80,1 \\
13 & 1000 & 750 & 4 & 66,9 \\
\hline \hline
\end{tabular}

After evaluate each of the experimental runs, were obtained in specific cases removal of COD close to $80 \%(+/-$ 0.40 ) varying concentrations of $\mathrm{H}_{2} \mathrm{O}_{2}, \mathrm{FeSO}_{4}$ at different $\mathrm{pH}$ values (Table III).
Was obtained a removal of $80 \%$ using 1000 ppm of $\mathrm{H}_{2} \mathrm{O}_{2}$ and 1000 ppm of $\mathrm{FeSO}_{4}$ into the sample at pH 5 (Table III, Fig. 1); likewise was reached $79.5 \%$ of removal when the dosage of $\mathrm{H}_{2} \mathrm{O}_{2}$ was reduced to $500 \mathrm{ppm}$ reacting with 1000 ppm of $\mathrm{FeSO}_{4}$ working the sample to $\mathrm{pH} 4$ (Table III, Fig. 1).

Some studies as [22] reports that the oxidation by Fenton reaction can remove approximately 20 to $80 \%$ of COD present in the leachate. [17] reports a $68 \%$ COD removal only with Fenton oxidation and reaches values of $86 \%$ when it is combined with a coagulation process, are reported similar cases in which was obtained a total removal between $63 \%$ and $71 \%$ combining Fenton process with other systems [2], [11].

[23] obtains a removal of $61 \%$ at 45 minutes of the reaction, obtaining the maximum efficiency of $62.9 \%$ after $60 \mathrm{~min}$; therefore, there is a tendency to increase the removal rate over time.

In our case, the reaction time was two hours and superior results were obtained. The optimum $\mathrm{pH}$ was set at 4 because, in this, the removals were high with a lower dosage of reagents (Table III, Fig. 1).

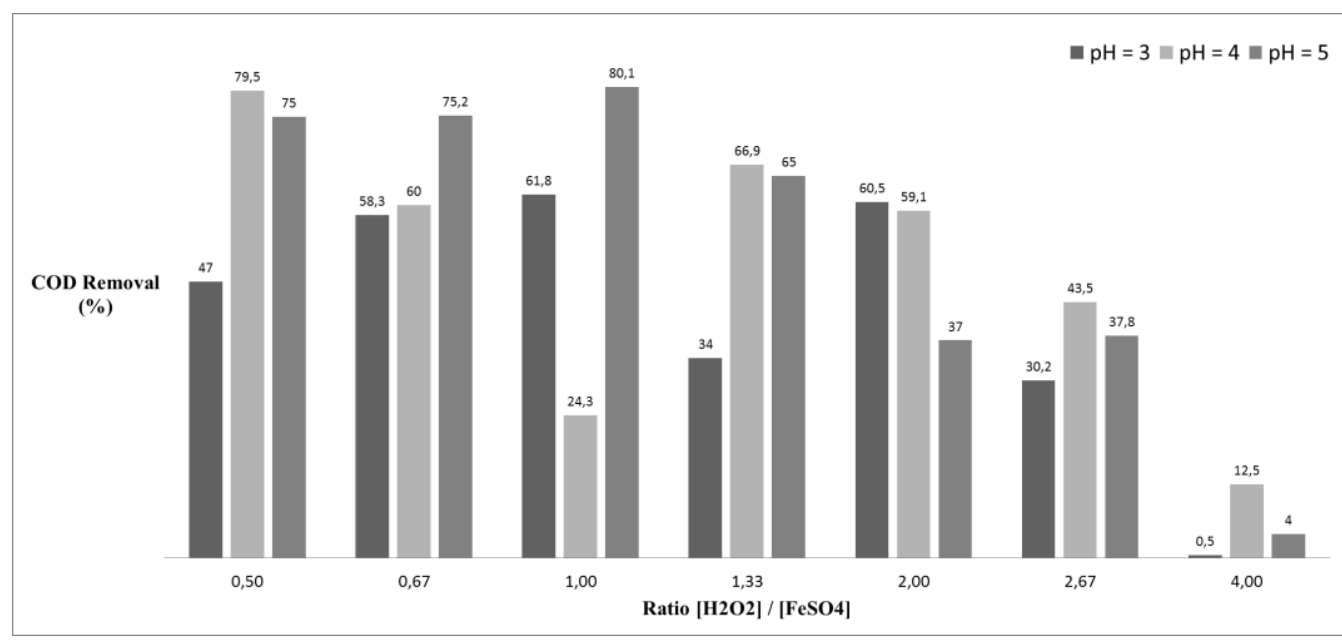

Fig. 1. Percentage of COD removal efficiency versus ratio $[\mathrm{H} 2 \mathrm{O} 2] /[\mathrm{Fe} 2+]$ achieved at $\mathrm{pH}=3, \mathrm{pH}=4$, and $\mathrm{pH}=5$.

Ref. [4], [24] in his studies established that the optimum $\mathrm{pH}$ for the Fenton reaction is in the range of 2-4 and that the system can work at values near 5 , but not on this because the efficiency of treatment would decrease significantly.

As for the concentration of reactants [10], [25] establish an optimal ratio of $\mathrm{H}_{2} \mathrm{O}_{2} / \mathrm{Fe}$ (II) between 1.5-3. In this particular case, the ratio with greater efficiency was obtained with values of 1 and 0.5 , achieving removals of $80 \%$ and $79.45 \%$ respectively (Fig. 1).

In addition to this it was determined that with Fenton process is obtained significant removals in other parameters such as those showed in Table IV.

TABLE IV: RESULTS OF OTHERS PARAMETERS REMOVAL

\begin{tabular}{cc}
\hline \hline Parameter & Removal $(\%)$ \\
\hline Nitrates & $39( \pm 0.59)$ \\
Phosphates & $89( \pm 0.50)$ \\
Turbidity & $79( \pm 0.81)$ \\
\hline \hline
\end{tabular}

\section{A. Process Optimization}

Statistical analysis established that significant process values correspond to the doses of $\mathrm{H}_{2} \mathrm{O}_{2}$ and $\mathrm{FeSO}_{4}$ used in the oxidation.

With this information the stationary point of the process which result to be a theoretical maximum where COD removal was set at $81.4 \%$, using a dose of $\mathrm{H}_{2} \mathrm{O}_{2}$ of $312 \mathrm{ppm}$, $1086 \mathrm{ppm}$ of $\mathrm{FeSO}_{4}$ working of the sample to $\mathrm{pH} 4$ (Fig. 2).

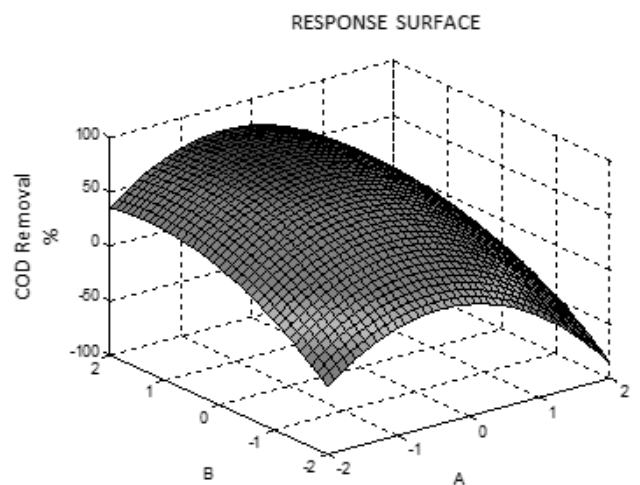

Fig. 2. Response surface models for COD removal efficiency at pH 4.

The theoretical value of \% removal is slightly higher than 
that found in the experimentation carried out. The concentrations of reactants and $\mathrm{pH}$ are very close to those used in experiment 3 .

\section{CONCLUSIONS}

Fenton was effectively used to reduce concentrations of COD of landfill leachate. The maximum amount of COD that could be removed by the Fenton's treatment was $79.5 \%$ of the initial value with a concentration of $500 \mathrm{ppm}$ of $\mathrm{H}_{2} \mathrm{O}_{2}$ and 1000 ppm of $\mathrm{FeSO}_{4}$ at pH 4, thus establishing an optimum working radius $\mathrm{H}_{2} \mathrm{O}_{2} / \mathrm{FeSO}_{4}$ equal to 0.5 .

Through Box-Behnken statistical analyses were determinates the significant factors, which correspond to the concentration of $\mathrm{H}_{2} \mathrm{O}_{2}$ and $\mathrm{FeSO}_{4}$. The process was optimized, reaching a theoretical removal of $81 \%$ at concentrations of $312 \mathrm{ppm}$ of $\mathrm{H}_{2} \mathrm{O}_{2}$ and 1087 ppm of $\mathrm{FeSO}_{4}$ at $\mathrm{pH} 4$.

A trend, experimental and theoretical it is noted that decreasing the ratio $\left[\mathrm{H}_{2} \mathrm{O}_{2}\right] /\left[\mathrm{Fe}^{2+}\right]$ increases the efficiency of removal of $\mathrm{COD}$ at $\mathrm{pH} 4$. Whereas at $\mathrm{pH} 5$ and $\mathrm{pH} 3$ with decreasing the ratio decreases the efficiency. Therefore a dependence of peroxide greater than the iron is noticed; so an excess in hydrogen peroxide affects negatively to the process.

Usually the Fenton process achieves greater efficiency at $\mathrm{pH}$ acids. In this matrix shows that as the $\mathrm{pH}$ decreases, the efficiency decreases.

\section{ACKNOWLEDGMENT}

The authors are grateful to the local government of Loja (Ecuador) - GAD for their full collaboration.

\section{REFERENCES}

[1] Y. Chen, C. Liu, J. Nie, S. Wu, and D. Wang, "Removal of COD and decolorizing from landfill leachate by Fenton's reagent advanced oxidation," Clean Technol. Environ. Policy, vol. 16, no. 1, pp. 189-193, Apr. 2013.

[2] W. G. Moravia, M. C. S. Amaral, and L. C. Lange, "Evaluation of landfill leachate treatment by advanced oxidative process by Fenton's reagent combined with membrane separation system," Waste Manag., vol. 33, no. 1, pp. 89-101, Jan. 2013.

[3] M. G. Lak, M. R. Sabour, A. Amiri, and O. Rabbani, "Application of quadratic regression model for Fenton treatment of municipal landfill leachate.,"Waste Manag., vol. 32, no. 10, pp. 1895-902, Oct. 2012.

[4] S. K. Singh and W. Z. Tang, "Statistical analysis of optimum Fenton oxidation conditions for landfill leachate treatment," Waste Manag., vol. 33, no. 1, pp. 81-88, Jan. 2013.

[5] D. Venu, R. Gandhimathi, P. V. Nidheesh, and S. T. Ramesh, "Treatment of stabilized landfill leachate using peroxicoagulation process," Sep. Purif. Technol., vol. 129, pp. 64-70, May 2014.

[6] A. M. Schiopu and M. Gavrilescu, "Options for the treatment and management of municipal landfill leachate: Common and specific issues," CLEAN — Soil, Air, Water, vol. 38, no. 12, pp. 1101-1110, Dec. 2010.

[7] P. Kjeldsen, M. A. Barlaz, A. P. Rooker, A. Baun, A. Ledin, and T. H. Christensen, "Present and long-term composition of MSW landfill leachate: A review," Crit. Rev. Environ. Sci. Technol., vol. 32, no. 4, pp. 297-336, Oct. 2002.

[8] A. Anfruns, J. Gabarró, R. Gonzalez-Olmos, S. Puig, M. D. Balaguer, and J. Colprim, "Coupling anammox and advanced oxidation-based technologies for mature landfill leachate treatment," J. Hazard. Mater. vol. 258-259, pp. 27-34, Aug. 2013.

[9] C. Ricordel and H. Djelal, "Treatment of landfill leachate with high proportion of refractory materials by electrocoagulation: System performances and sludge settling characteristics," J. Environ. Chem. Eng., vol. 2, no. 3, pp. 1551-1557, Sep. 2014.

[10] D. Hermosilla, M. Cortijo, and C. P. Huang, "Optimizing the treatment of landfill leachate by conventional Fenton and photo-fenton processes.," Sci. Total Environ., vol. 407, no. 11, pp. 3473-3481, May 2009.

[11] A. R. Abood, J. Bao, J. Du, D. Zheng, and Y. Luo, "Non-biodegradable landfill leachate treatment by combined process of agitation, coagulation, SBR and filtration," Waste Manag., vol. 34, no. 2, pp. 439-447, Feb. 2014.

[12] M. A. Zazouli, Z. Yousefi, A. Eslami, and M. B. Ardebilian, "Municipal solid waste landfill leachate treatment by fenton, photo-fenton and fenton-like processes: Effect of some variables," $J$. Environ. Heal. Sci. Eng., vol. 9, no. 1, 2012.

[13] Y. Deng and J. D. Englehardt, "Treatment of landfill leachate by the Fenton process.," Water Res., vol. 40, no. 20, pp. 3683-3694, Dec. 2006.

[14] D. Rubio, E. Nebot, J. F. Casanueva, and C. Pulgarin, "Comparative effect of simulated solar light, $\mathrm{UV}, \mathrm{UV} / \mathrm{H}_{2} \mathrm{O}_{2}$ and photo-Fenton treatment (UV-Vis $\left./ \mathrm{H}_{2} \mathrm{O}_{2} / \mathrm{Fe}^{2+}{ }^{3+}\right)$ in the Escherichia coli inactivation in artificial seawater.," Water Res., vol. 47, no. 16, pp. 6367-6379, Oct. 2013.

[15] M. Ahmadian, S. Reshadat, N. Yousefi, S. H. Mirhossieni, M. R. Zare, S. R. Ghasemi, N. Rajabi Gilan, R. Khamutian, and A. Fatehizadeh, "Municipal leachate treatment by Fenton process: effect of some variable and kinetics," J. Environ. Public Health, vol. 2013, p. 169682 , Jan. 2013.

[16] S. Renou, J. G. Givaudan, S. Poulain, F. Dirassouyan, and P. Moulin, "Landfill leachate treatment: Review and opportunity," J. Hazard. Mater., vol. 150, no. 3, pp. 468-493, Feb. 2008.

[17] A. Talebi, N. Ismail, T. T. Teng, and A. F. M. Alkarkhi, "Optimization of COD, apparent color, and turbidity reductions of landfill leachate by Fenton reagent," Desalin. Water Treat., vol. 52, no. 7-9, pp. 1524-1530, Feb. 2014

[18] J. Zhu, "Optimization of Fenton process for treatment of landfill leachate using response surface methodology," Asian J. Chem., vol. 26, no. 19 , pp. 6630-6634, 2014.

[19] A. P. H. Association, Stand. Methods Exam, 1998.

[20] R. Myers, D. Montgomery, and C. Anderson-Cook, "Response surface methodology: Process and product optimization using designed experiments," Wiley Series in Probability and Statistics, 2009.

[21] T. Wani, A. Ahmad, and S. Zargar, "Use of response surface methodology for development of new microwell-based spectrophotometric method for determination of atrovastatin calcium in tablets," Chem. Cent., 2012.

[22] H. Li, S. Zhou, Y. Sun, and J. Lv, "Application of response surface methodology to the advanced treatment of biologically stabilized landfill leachate using Fenton's reagent," Waste Manag., vol. 30, no. 11, pp. 2122-2129, Nov. 2010.

[23] B. Pieczykolan, I. Płonka, K. Barbusiński, and M. Amalio-Kosel, "Comparison of Landfill leachate treatment efficiency using the advanced oxidation processes," Arch. Environ. Prot., vol. 39, no. 2, pp. 107-115, Jun. 2013

[24] O. S. Amuda, I. A. Amoo, and O. O. Ajayi, "Performance optimization of coagulant/flocculant in the treatment of wastewater from a beverage industry," J. Hazard. Mater., vol. 129, no. 1-3, pp. 69-72, Feb. 2006.

[25] H. Zhang, X. Wu, and X. Li, "Oxidation and coagulation removal of COD from landfill leachate by Fered-Fenton process," Chem. Eng. J., vol. 210, pp. 188-194, Nov. 2012.

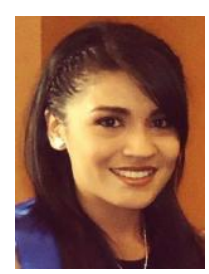

María Luisa Santín Gusmán was born in Loja, Ecuador in 1991. She obtained the chemical engineer degree in Technical Particular University of Loja, Ecuador. Actually she is collaborating in the Chemical Department (Environmental Engineering Division) in water analysis issues.

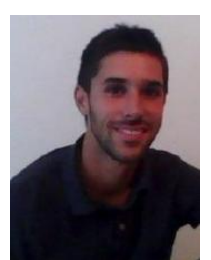

Javier Moreno-Andrés was born in Granada, Spain in 1986. He graduated on environmental sciences from the University of Granada, Spain in 2011 and completed an MSc degree in water management from University of Cádiz, Spain. Now he is a Ph.D. student in the Environmental Technologies Department, University of Cádiz.

His Ph.D. research interest is in the area of water treatment, specifically water disinfection based in advanced oxidation processes.

His research focuses on find new sustainable and effective solutions in water treatment. He has published one international journal paper and one international conference paper. 


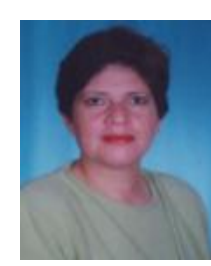

Mónica Jacqueline Cisneros Abad was born in Loja, Ecuador in 1966. She is a professor and the head of the Chemical Department, which is in environmental engineering area.

She graduated in civil engineer from Technical Particular University of Loja, Ecuador and obtained the MSc. Geological engineer title in the University of Granada, Spain.

Her research interests are based on environmental engineering laboratories, focusing on water aspects.

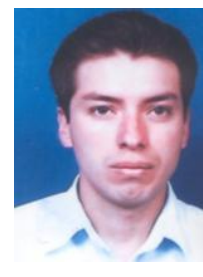

Silvio David Aguilar Ramirez was born in Zaruma,

Ecuador in 1977. He is a professor at Environmental Engineering Section in Technical Particular University of Loja, Ecuador as well as a research assistant at the Chemical Department.

He obtained his degree in chemical engineering from Technical Particular University of Loja, Ecuador and obtained an MSc degree in water management from University of Cádiz, Spain.

He has published two papers in scientific journals. His research areas are environmental analysis, water treatment and bioaccumulation of heavy metals in plants. 